\title{
Double-immunostaining of $p 63$ protein and cytokeratin 8 in pleomorphic adenomas
}

\author{
Masahiro Wato ${ }^{1}$, Hirotaka Kon-i ${ }^{2}$, Yoichiro Taguchi ${ }^{3}$, Masatoshi Ueda ${ }^{3}$, Ken-ichi Uobe ${ }^{1}$, \\ Kazuya Masuno ${ }^{1}$, Kazuya Tominaga ${ }^{1}$, Tetsunari Nishikawa ${ }^{1}$, Akio Tanaka ${ }^{1}$ \\ ${ }^{\prime}$ Department of Oral Pathology, Osaka Dental University, Hirakata, Japan \\ ${ }^{2}$ Division of Interdisciplinary Dentistry for Postgraduate Trainees, Osaka Dental University, Hirakata, Japan \\ ${ }^{3}$ Department of Periodontology, Osaka Dental University, Hirakata, Japan
}

Abstract: Salivary gland pleomorphic adenoma (PA) has morphological diversity in tumor cell arrangements within its characteristic myxochondroid stroma, although it remains uncertain whether neoplastic myoepithelial or ductal cells are responsible for such diversity. To analyze the morphological and functional characteristics of the constituent cells of salivary gland PA, we investigated comparative expressions of $p 63$ gene products (P63) as a myoepithelial/basal cell marker as well as those of cytokeratin 8 (CK8) as a duct epithelial cell marker through the use of double-immunohistochemical staining. Formalin-fixed, paraffin-embedded sections of 10 samples each of PA and normal salivary gland were examined. In normal salivary glands, P63-positive myoepithelial cells were distinguished from CK8positive luminal cells of intercalated ducts. In PA, P63-positivity was observed in both luminal and basal cells of ductal structures, in spindle-shaped cells scattered in the myxoid stroma, and in peripheral cells of squamous-metaplastic foci, while CK8 was only positive in luminal cells of the ductal structures. Based on the simultaneous labeling of the two markers on same sections through double immunostaining, the ductal structures in PA were shown to be not functionally the same as normal ducts, and hence it is possible to consider that most of the PA cells shared myoepithelial phenotypes.

[Oral Med Pathol 2009; 14: 49-54 doi: 10.3353/omp.14.49]

Key words: cytokeratin 8, double-immunostaining, neoplastic myoepithelial cells, p63, pleomorphic adenoma

Correspondence: Masahiro Wato, Department of Oral Pathology, Osaka Dental University, 8-1, Kuzuhahanazono-cho, Hirakata 573-1121, Japan

Phone: +81-72-864-3057, Fax: +81-72-864-3157, E-mail: wato@cc.osaka-dent.ac.jp

\section{Introduction}

Pleomorphic adenoma (PA) is the most common benign tumor arising in both major and minor salivary glands. It exhibits the proliferation of epithelial tumor cells with a bidirectional line of differentiation into duct luminal and myoepithelial/basal cell types. These two major types of tumor cells may potentially contribute to the morphological diversity of salivary gland tumors. Therefore, the histological features of PA and other salivary gland tumors (1-3) often resemble each other.

Immunohistochemically, $\alpha$-smooth muscle actin (SMA), calponin, cytokeratin (CK) 14, and p63 gene products (P63) are considered to be markers of myoepithelial cells, and antibodies against these molecules have frequently been used to identify myoepithelial differentiation not only in salivary gland tumors (4-11) but also in breast (12-13) and prostate (14) cancers, because neoplastic myoepithelial cells play a critical role in generating characteristic tissue architectures which are specific to each salivary gland tumor. On the other hand, epithelial membrane antigen (EMA), carcinoembryonic antigen (CEA), pan-keratin (AE1/AE3 antibody), CK7, and CK8 have been immunolocalized in luminal epithelial cells of the salivary ducts (15-21).

Double immunohistochemical staining is a useful method to demonstrate these two different cellular phenotypes simultaneously on the same tissue sections, and hence it is widely utilized for the differential diagnoses of salivary gland (22) and breast (23) tumors. However, it is important to select antibodies, especially those for CKs in contrasting specific unit structures of salivary gland tumors, because some CKs are shared by both myoepithelial and luminal cells. Double immunohistochemical staining should also be useful in distinguishing nuclei from the cytoplasm at the same time. 
Table 1. Clinicopathological features of pleomorphic adenoma cases

\begin{tabular}{cll}
\hline case \# & age \& sex & location \\
\hline 1 & $43 \mathrm{M}$ & parotid gland \\
2 & $30 \mathrm{~F}$ & palate \\
3 & $60 \mathrm{M}$ & buccal mucosa \\
4 & $60 \mathrm{~F}$ & submandibular gland \\
5 & $63 \mathrm{M}$ & lip \\
6 & $63 \mathrm{~F}$ & palate \\
7 & $42 \mathrm{M}$ & submandibular gland \\
8 & $56 \mathrm{~F}$ & parotid gland \\
9 & $25 \mathrm{M}$ & parotid gland \\
10 & $26 \mathrm{M}$ & palate \\
\hline
\end{tabular}

Table 2. Primary antibodies used in immunohistochemistry

\begin{tabular}{lllll}
\hline $\begin{array}{l}\text { antibody } \\
\text { against }\end{array}$ & clone & dilution & $\begin{array}{l}\text { antigen } \\
\text { retrieval }\end{array}$ & distributor \\
\hline $\begin{array}{l}\text { cytokeratin } 8 \\
\text { p63 protein }\end{array}$ & 7-Jul & $1: 50$ & autoclave & Novocastra \\
\hline
\end{tabular}

In this study, we identified an appropriate combination of antibodies for discriminating between luminal and myoepithelial cells and applied it for characterization of tumor cell diversity in PA.

\section{Materials and methods}

\section{Tissue specimens}

Formalin-fixed, paraffin-embedded sections of 10 samples each of PA and normal salivary gland tissues were obtained from Osaka Dental University Hospital. The histopathological diagnoses of these specimens were independently confirmed by two oral pathologists. The age of PA patients ranged between 25 and 63 years, with a mean of 47 . The male:female ratio was 6:4 (Table 1). Tumor locations included both major ( 3 parotid and 2 submandibular) and minor (3 palatal, 1 each buccal and lip) salivary glands.

\section{Double immunohistochemical staining}

Paraffin sections were deparaffinized and autoclaved at $121^{\circ} \mathrm{C}$ for $15 \mathrm{~min}$ in $1 \mathrm{mM}$ Tris-EDTA buffer ( $\mathrm{pH} 9.0$ ) for antigen retrieval. Endogenous peroxidase activities were blocked with $0.003 \% \mathrm{H}_{2} \mathrm{O}_{2}$. Sections were then reacted with the anti-P63 mouse monoclonal antibody (clone 7JUL, Novocastra Laboratories Ltd, Newcastle upon Tyne, UK, diluted at 1:50) for $1 \mathrm{hr}$ at room temperature. Following incubation, the sections were incubated with peroxidaseconjugated dextranpolymer (EnVision+, anti-mouse, Dako, Glostrup, Denmark) for $30 \mathrm{~min}$ at RT. Reaction products were visualized with 3', 3-diaminobenzidine (Liquid DAB,

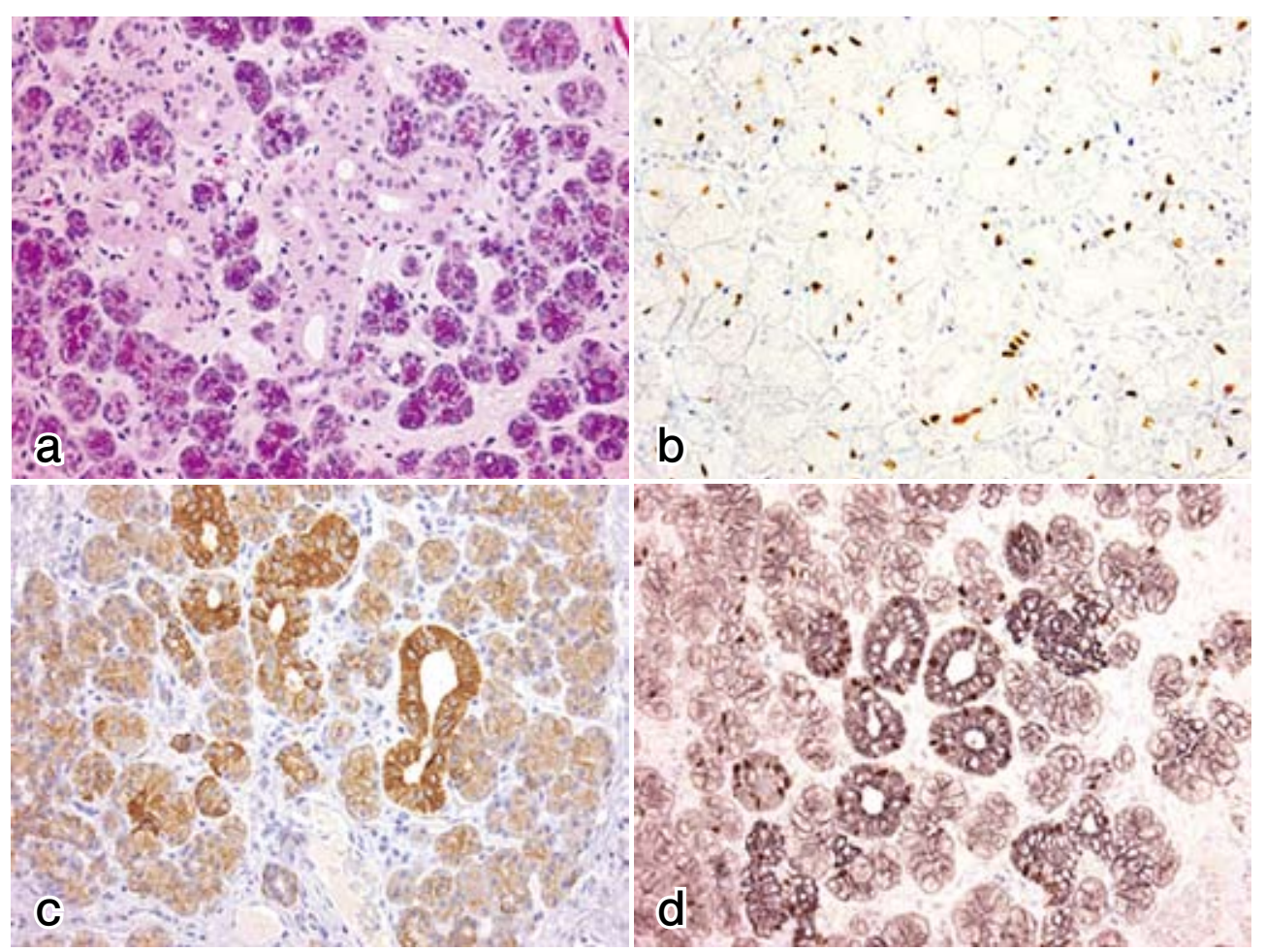

Fig. 1. Comparison of double and single immunohistochemical stainings for p63 protein (P63) and cytokeratin (CK) 8 in normal salivary glands. Hematoxylin and eosin (HE) stain (a), immunoperoxidase stain for P63 (b) and CK8 (c), hematoxylin counterstain; doubleimmunoperoxidase stain for P63 (brown) and CK8 (charcoal gray) (d), no counterstain, $x$ 200. In normal salivary gland (a), P63 was positive in myoepithelial cells surrounding both acini and intercalated ducts (b). CK8 was positive in the cytoplasm of acinar and luminal cells of intercalated ducts (c). Double-immunostained, P63 (brown) and CK8 (charcoal gray) were clearly contrasted in their specific sites at the same area (d). 


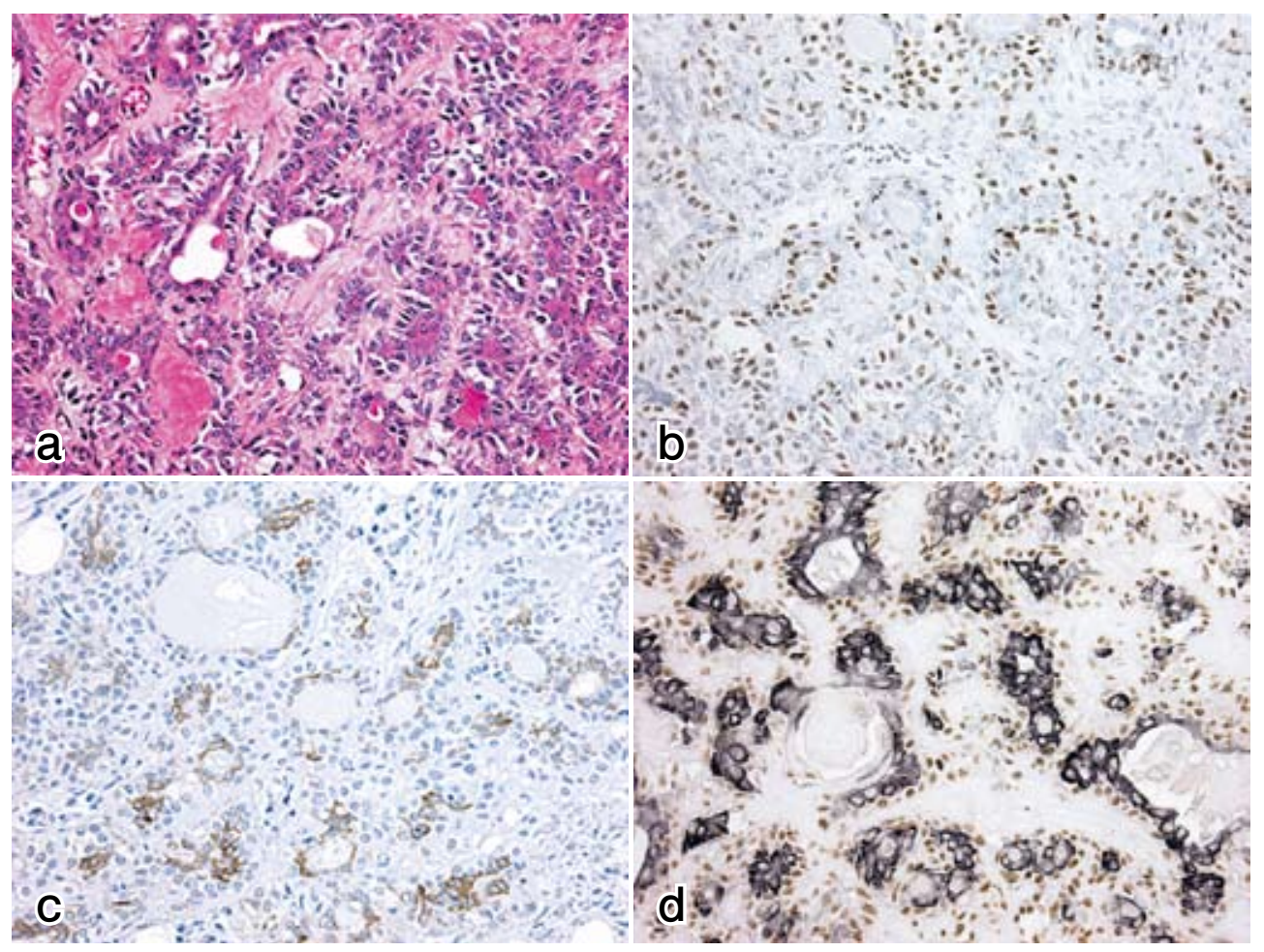

Fig. 2. Immunohistochemistry for $\mathrm{P} 63$ and CK8 in ductal structures of pleomorphic adenoma. HE stain (a), immunoperoxidase stain for P63 (b) and CK8 (c), hematoxylin counterstain; and double-immunoperoxidase stain for P63 (brown) and CK8 (charcoal gray) (d), no counterstain, $\times 200$. In ductal structures of pleomorphic adenoma (a), P63 was positive in peripheral tumor cells forming ductal structures (b), while CK8 was localized within the cytoplasm of tumor cells located in the luminal side (c). In double-immunostaining, their contrastive immunolocalizations were confirmed in the same area, indicating that pleomorphic adenoma cells were differentiated into two different cells types, duct epithelial and myoepithelial, when they formed ductal structures (d).

Dako). Following visualization of P63, the sections were further reacted with an anti-CK8 mouse monoclonal antibody $(35 \beta \mathrm{H} 11$, Dako, diluted at 1:50) for $30 \mathrm{~min}$ at room temperature and then incubated with EnVision+ for $30 \mathrm{~min}$ at room temperature (Table 2). Their reaction products were subsequently visualized with nickel-DAB (Vector Laboratories, Inc, Burlingame, CA, USA). In addition to the double immunostaining, single immunostaining experiments were also performed for controls. For single stainings, sections were counterstained with Mayer's hematoxylin, whereas double-stained sections were not counterstained.
For the control sections, the primary antibodies were replaced with normal mouse $\mathrm{IgG}$.

This research plan was approved by the Ethics Committee of Osaka Dental University (approval number 080915).

\section{Results}

\section{Normal salivary glands}

In normal gland (Fig. 1a), the expression of P63 was observed in the nuclei of myoepithelial cells of acini or intercalated ducts, or in the nuclei of basal cells of striated

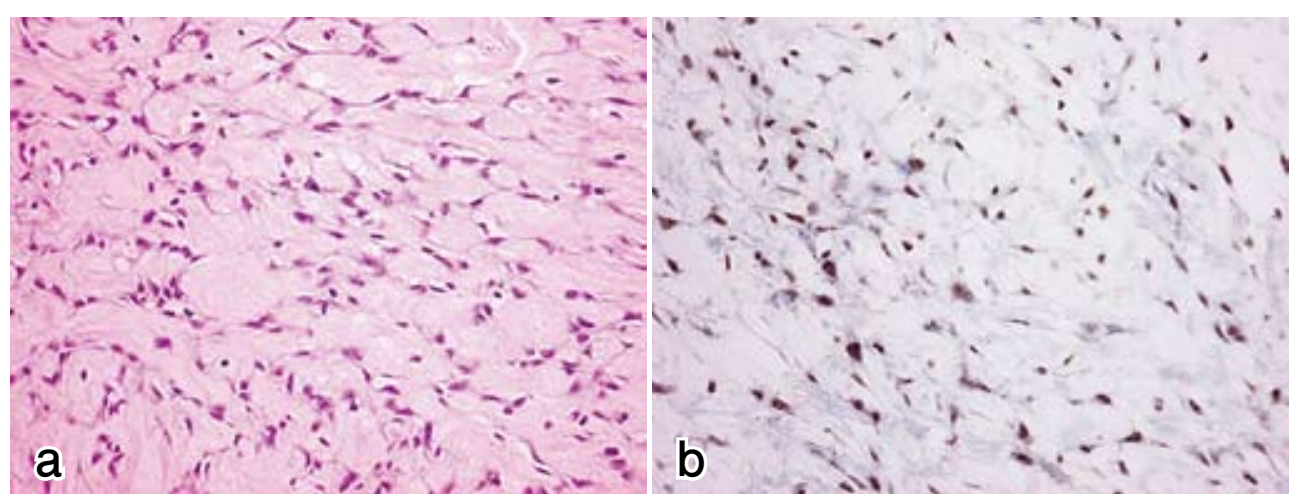

Fig. 3. Immunohistochemistry for P63 and CK8 in chondromyxoid areas of pleomorphic adenoma. HE stain (a) and double-immunoperoxidase stain for P63 (brown) and CK8 (charcoal gray) (b), no counterstain, $\times 200$. In chondromyxoid areas of pleomorphic adenoma (a), many stellate-shaped cells were positive for P63 but not for CK8 (b). 

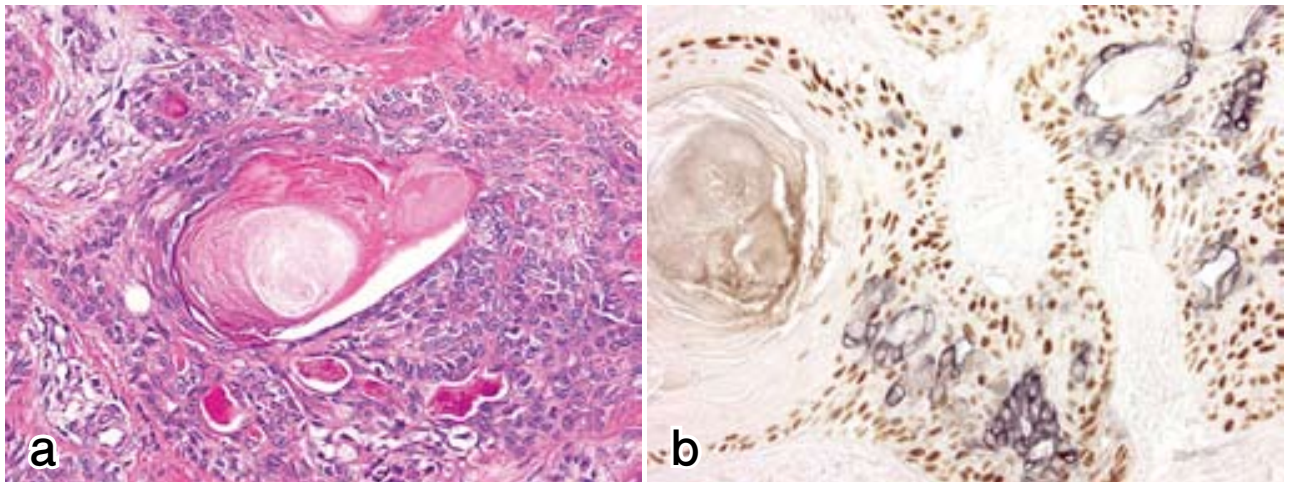

Fig. 4. Immunohistochemistry for P63 and CK8 in squamous metaplastic areas of pleomorphic adenoma. HE stain (a) and double-immunoperoxidase stain for P63 (brown) and CK8 (charcoal gray) (b), no counterstain, $\times 200$. In squamous metaplastic areas of pleomorphic adenoma (a), P63 was localized in basal cells as well as squamous metaplastic cells but not in keratinized cells. CK8 was sporadically positive in acanthomatous cells (b).

ducts (Fig. 1b). CK8 expression was observed in the cytoplasm of luminal cells of intercalated, striated and excretory ducts as well as acinar cells but not in myoepithelial or basal cells (Fig. 1c). With double-immunostaining for the two molecules, CK8-positive luminal and acinar cells were clearly contrasted with P63 positive myoepithelial or basal cells in acini, intercalated ducts, or excretory ducts at the same time. Thus, it was considered to be a general tendency that basal cells were positive for P63 and luminal cells were positive for CK8 in any salivary components with two-celllayer structures (Fig. 1d).

\section{Pleomorphic adenoma}

In this study, four histological architectures characteristic to pleomorphic adenoma were selected for the comparative immunolocalizations between P63 and CK8: ductal (Fig. 2a), chondromyxoid (Fig. 3a), squamous metaplastic (Fig. 4a), duct-predominant (Fig. 5a), and solid or sheet-like (Fig. 6a).

In ductal structure predominant areas (Fig. 2a), the expression of $\mathrm{P} 63$ was evident in nuclei of basal/peripheral cells of the ductal structures when they were composed of a two-cell layering of luminal and basal/peripheral cells (Fig. 2b). CK8 was observed in the cytoplasm of cuboidal cells located in the luminal side (Fig. 2c). Using the doubleimmunostaining method, CK8-positive luminal cells and P63-positive basal/peripheral cells were clearly distinguished from each other. The basal/peripheral cells were considered to be neoplastic myoepithelial (NME) cells.

In the chondromyxoid area (Fig. 3a), P63 was strongly positive in spindle- or stellate-shaped cells, but CK 8 was not apparent in any of those cells (Fig. 3b). The doubleimmunostaining method was useful in demonstrating the P63-positive cell predominant in the chondromyxoid area.

In tumor cell nests with pronounced squamous metaplasia, P63 positive cells circumscribed keratin cores, while CK8 was only observed in a small number of acanthomatous cells in the center (Fig. 4b).

In the duct-predominant area (Fig. 5a), CK8-expression was discernible in luminal cells, while P63-positive cells were rather small in number but definitely located in the periphery of tumor cell foci (Fig. 5b).

In the solid or sheet-like area (Fig. 6a), CK8 was positive in so-called epithelioid cells with plentiful eosinophilic cytoplasm and plump nuclei, which occupied the majority part of tumor cell nests. In contrast, P63-positive cells were occasionally detected at the periphery of foci, in which their cell density was much less than that of CK8-positive
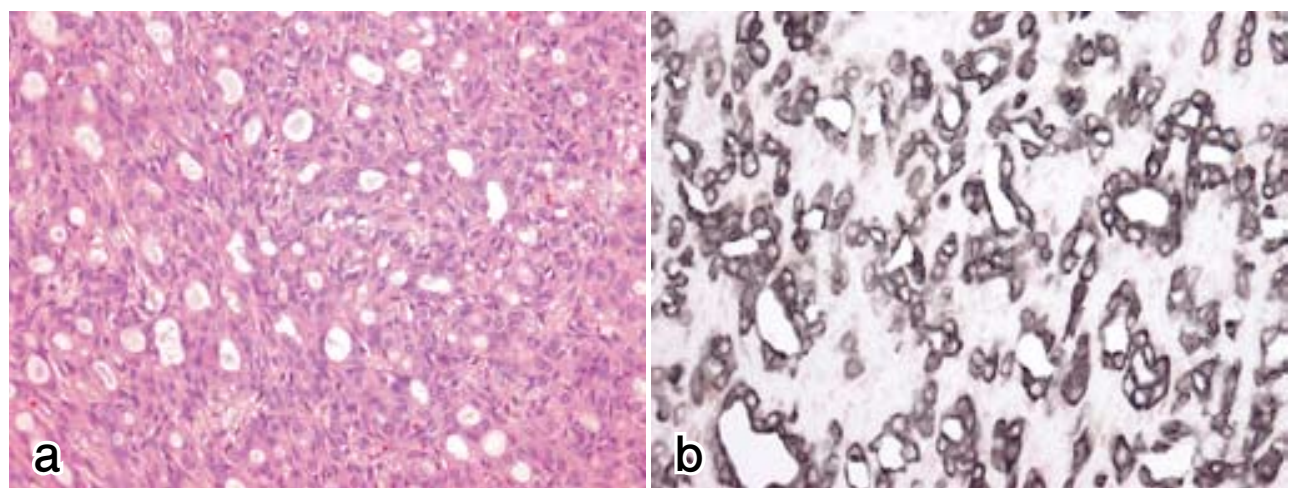

Fig. 5. Immunohistochemistry for P63 and CK8 in duct-predominant areas of pleomorphic adenoma. HE stain (a) and double-immunoperoxidase stains for P63 (brown) and CK8 (charcoal gray) (b), no counterstain, $\times 200$. In duct-predominant areas of pleomorphic adenoma (a), CK8 was localized in luminal cells of ductal structures, while P63-positive cells were occasionally observed in their basal or peripheral part (b). 


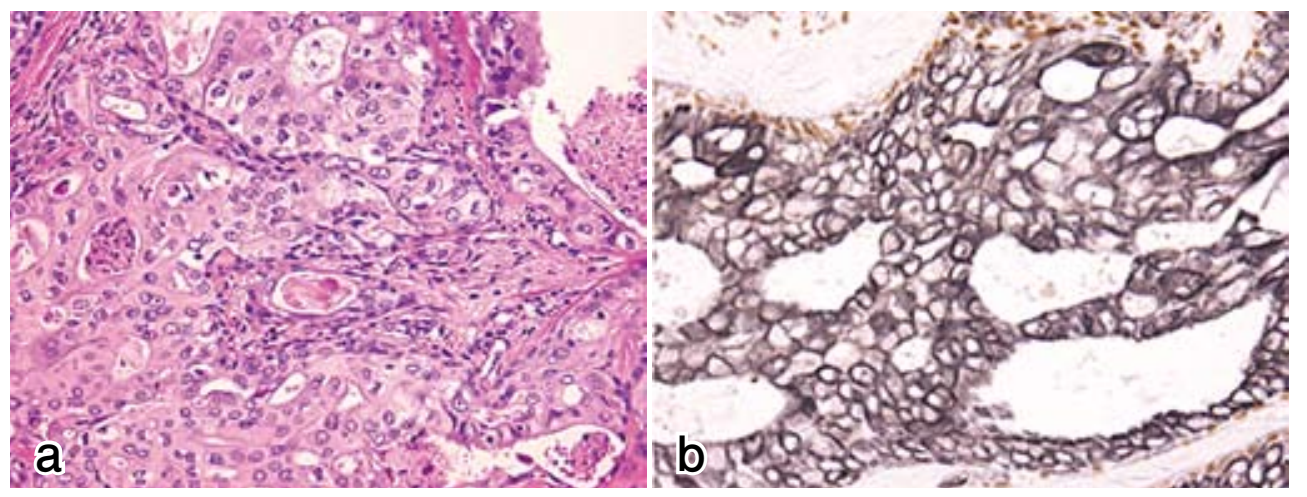

Fig. 6. Immunohistochemistry for $\mathrm{P} 63$ and CK8 in epithelioid differentiation areas of pleomorphic adenoma. HE stain (a) and double-immunoperoxidase stains for P63 (brown) and CK8 (charcoal gray) (b), no counterstain, $\times 200$. In tumor cell foci with epithelioid differentiation of pleomorphic adenoma (a), most of the epithelioid tumor cells with abundant cytoplasm were positive for CK8 and peripheral cells were positive for P63 (b).

epithelioid cells (Fig. 6b). Neither P63 nor CK8 was apparently expressed in plasmacytoid cells (not shown).

\section{Discussion}

Since double layering of tumor cells is one of the characteristic histological features of salivary gland tumors such as pleomorphic adenoma, an optimal doubleimmunostaining method using suitable antibodies has been eagerly anticipated for understanding the tumor tissue architectures. In the present study, we were successful in distinguishing the neoplastic myoepithelial cells from luminal tumor cells of the ductal structures of PA by using the double-immunohistochemical staining for P63 and CK8.

Smooth muscle actin (SMA) and calponin have been used as immunohistochemical markers for normal and neoplastic myoepithelial cells, although these markers demonstrate not only myoepithelial cells but also smooth muscle cells of blood vessels (4). In contrast, CK14, another myoepithelial marker, has been utilized for both myoepithelial and basal cells of salivary ducts or duct-like structures (11). While these three myoepithelial markers are immunolocalized in the cytoplasm, P63 was expressed in the nuclei of myoepithelial cells of normal salivary gland and also in the nuclei of basal/peripheral cells of salivary gland tumor cell foci (7-8). Our present finding - that P63 was only localized in nuclei of abluminal cells of the sheet-like area, spindle-shaped cells, and squamous metaplastic cells of pleomorphic adenoma-indicates that P63 is a useful marker of neoplastic myoepithelial cells especially when it is applied to double-immunostainings.

Epithelial membrane antigen (EMA), carcinoembryonic antigen (CEA), CK7, and CK8 are considered to be markers of luminal cells in duct-like structures of pleomorphic adenoma (16). EMA and CEA are expressed in both the cell membrane and cytoplasm of luminal cells, and the staining reaction of these markers has a predilection to extend around the luminal side. Because of their diffuse staining tendencies, the antibodies against these two molecules are not suitable for double-immunostaining.
Wide spectrum CK (AE1/AE3 antibody) is a general epithelial marker, but it is not appropriate as a marker for luminal cells of ductal structures. Ichihara et al. reported that double-immunostaining of P63 as well as the high molecular weight $\mathrm{CK}$ were useful for the reproducible classification of papillary breast lesions (23). However, high molecular weight $\mathrm{CK}$ is expressed in both luminal and abluminal cells, hence it is not suitable for double-immunostaining of PA. For this reason, we did not adopt the antibodies for high molecular weigh $\mathrm{CK}$, including AE1/AE3, in the present study. Luminal cells of ductal structures are positive for CK7, CK8, CK18, and CK19 (17). Antibodies against CK7 and CK20 were used to differentiate adenocarcinomas of various primary sites (24), although CK7 is widely observed in duct luminal cells as well as in spindle-shaped myoepithelial and squamous metaplastic cells (21). Plasmacytoid cells were stained with antibodies against CK7, CK8, CK14, and CK19 (17-18, 25). Our present results showed the consistent CK8 localization in the luminal cells of any kind of normal duct as well as in neoplastic luminal cells in pleomorphic adenoma. The duct epithelial cells were commonly stained with the antibody CAM5.2 (26). However, CAM5.2 is known to crossreact with CK7 and CK8. Therefore, CK8 may be the most useful marker for luminal cells in salivary ductal structures, especially in the case of double-immunostaining for PA.

Which chromogens to use is also an important issue for the double-immunostaining method. In this study using formalin-fixed specimens, we obtained excellent results when DAB was combined with NI-DAB.

The combination of P63 and CK8 antibodies in the identification of neoplastic myoepithelial and luminal cells, respectively, was demonstrated to be useful for their doubleimmunostaining to investigate the morphological diversity of PA. The results indicated that the morphological diversity of pleomorphic adenoma depends on the proportion between neoplastic myoepithelial and luminal cells of each tumor cell nest. In addition, this double-immunostaining method may have various potential applications for research on other salivary gland tumors. 


\section{References}

1. Everson JW, Kusafuka K, Stenman G, Nagao T. Pleomorphic adenoma. In: Barnes L, Eveson JW Reichart P, Sidransky D, ed. World Health Organization Classification of Tumours, Pathology \& Genetics of Head and Neck Tumours, IARC Press, Lyon, 2005; 254-58.

2. Ellis GL, Auclair PL. AFIP Atlas of Tumor Pathology, Fourth Series, Tumors of the Salivary Glands. Armed Forces Institute of Pathology, Washington, DC, 2008; 49-70.

3. Savera AT, Zarbo RJ. Defining the role of myoepithelium in salivary gland neoplasia. Adv Anat Pathol 2004; 11: 69-85.

4. Gugliotta P, Sapino A, Macrí L, Skalli O, Gabbiani G, Bussolati G. Specific demonstration of myoepithelial cells by anti-alpha smooth muscle actin antibody. J Histochem Cytochem 1988; 36: 659-63.

5. Ogawa Y, Toyosawa S, Ishida T, Ijuhin N. Keratin 14 immunoreactive cells in pleomorphic adenomas and adenoid cystic carcinomas of salivary glands. Virchows Arch 2000; 437: 58-68.

6. Weber A, Langhanki L, Schütz A, et al. Expression profiles of p53, p63, and p73 in benign salivary gland tumors. Virchows Arch 2002; 441: 428-36.

7. Bilal H, Handra-Luca A, Bertrand JC, Fouret PJ. p63 is expressed in basal and myoepithelial cells of human normal and tumor salivary gland tissues. J Histochem Cytochem 2003; 51:133-9.

8. Seethala RR, LiVolsi VA, Zhang PJ, Pasha TL, Baloch ZW. Comparison of p63 and p73 expression in benign and malignant salivary gland lesions. Head Neck 2005; 27: 696-02.

9. Emanuel P, Wang B, Wu M, Burstein DE. p63 immunohistochemistry in the distinction of adenoid cystic carcinoma from basaloid squamous cell carcinoma. Mod Pathol 2005; 18: 645-50.

10. Furuse C, Sousa SO, Nunes FD, Magalhães MH, Araújo VC. Myoepithelial cell markers in salivary gland neoplasms. Int J Surg Pathol 2005; 13: 57-65.

11. de Araújo VC, Altemani A, Furuse C, Martins MT, de Araújo NS. Immunoprofile of reactive salivary myoepithelial cells in intraductal areas of carcinoma ex-pleomorphic adenoma. Oral Oncol 2006; 42: 1011-6.

12. Barbareschi M, Pecciarini L, Cangi MG, et al. p63, a p53 homologue, is a selective nuclear marker of myoepithelial cells of the human breast. Am J Surg Pathol 2001; 25: 1054-60.

13. Leibl S, Gogg-Kammerer M, Sommersacher A, Denk H, Moinfar F. Metaplastic breast carcinomas: Are they of myoepithelial differentiation?: immunohistochemical profile of the sarcomatoid subtype using novel myoepithelial markers. Am J Surg Pathol 2005; 29: 347-53.
14. Chuang AY, DeMarzo AM, Veltri RW, Sharma RB, Bieberich CJ, Epstein JI. Immunohistochemical differentiation of high-grade prostate carcinoma from urothelial carcinoma. Am J Surg Pathol 2007; 31: 1246-55.

15. Takai Y, Dardick I, Mackay A, Burford-Mason A, Mori M. Diagnostic criteria for neoplastic myoepithelial cells in pleomorphic adenomas and myoepitheliomas. Immunocytochemical detection of muscle-specific actin, cytokeratin 14, vimentin, and glial fibrillary acidic protein. Oral Surg, Oral Med, Oral Pathol, Oral Radiol, Endod 1995; 79: 330-41.

16. Angelov, Dikranian K, Trosheva M. Immunomorphological characteristics of pleomorphic adenoma of salivary glands. Bull Group Int Rech Sci Stomatol Odontol 1996; 39: 67-75.

17. de Araújo VC, de Sousa SOM. Expression of different keratins in salivary gland tumours. Eur J Cancer B Oral Oncology 1996; 32B: 14-8.

18. de Araújo VC, de Sousa SO, Carvalho YR, de Araújo NS. Application of immunohistochemistry to the diagnosis of salivary gland tumors. Applied Immunohistochem Mol Morphol 2000; 8: 195-202.

19. de Soura SOM, de Araújo NS, Corrêa L, AMP Soubhia, de Araújo VC. Immunohistochemical aspects of basal cell adenoma and canalicular adenoma of salivary glands. Oral Oncol 2001; 37: 365-8.

20. Mărgăritescu CL, Florescu M, Raica M, Simionescu C, Mogoanta L, Preda E. The immunohistochemical profile of luminal epithelial neoplastic component from pleomorphic adenomas of salivary glands. Rom J Morpho Embryol 1999-2004; 45: 97-118.

21. Ihrler S, Zietz C, Sendelhofert A, Lang S, Blasenbreu-Vogt S, Löhrs U. A morphogenetic concept of salivary duct regeneration and metaplasia. Virchows Arch 2002; 440: 519-26.

22. Ihrler S, Weiler C, Hirschmann A, et al. Intraductal carcinoma is the precursor of carcinoma ex pleomorphic adenoma and is often associated with dysfunctional p53. Histopathology 2007; 51: 362-71.

23. Ichihara S, Fujimoto T, Hashimoto K, Moritani S, Hasegawa M, Yokoi T. Double immunostaining with p63 and highmolecular-weight cytokeratins distinguishes borderline papillary lesions of the breast. Pathol Int 2007; 57: 126-32.

24. Meer S, Altini M. CK7+/CK20- immunoexpression profile is typical of salivary gland neoplasia. Histopathology 2007; 51: 26-32.

25. Ogawa Y, Kishino M, Atsumi Y, et al. Plasmacytoid cells in salivary-gland pleomorphic adenomas: evidence of luminal cell differentiation. Virchow Arch 2003; 443: 625-34.

26. Sato K, Ueda Y, Shimasaki M, et al. Pleomorphic adenoma (benign mixed tumor) of the breast: a case report and review of the literature. Path Res Pract 2005; 201: 333-9. 